\title{
Artigos
}

Isadhora Araújo Lucena Silva' Maria de Fátima Gomes da Silva²

\section{A importância da brincadeira de faz de conta na educação infantil: sob o olhar de professoras}

\begin{abstract}
Resumo: Este artigo é um recorte de uma pesquisa de mestrado em educação que teve como objetivo principal investigar as contribuições de uma Brinquedoteca Universitária, criada na Universidade de Pernambuco, com o intuito de promover Formação Continuada para professores/as da Educação Infantil e também atender a crianças desse nível de escolarização, oferecendo-lhes experiências brincantes. 0 recorte aqui apresentado baseia-se nas concepções de professoras da Educação Infantil, refletindo sobre as contribuições da brincadeira de faz de conta para as crianças e para a prática pedagógica, a partir de uma das formações continuadas desenvolvidas na Brinquedoteca Universitária. Através da pesquisa-ação, foi possível concluir que a brincadeira de faz de conta contribui para a aprendizagem e 0 desenvolvimento da criança da Educação Infantil de forma imaginativa e criativa e que exerce, na prática pedagógica de professores/as, uma mais-valia pedagógica no que toca à necessária interação entre o brincar e o aprender.
\end{abstract}

Palavras-chaves: Brinquedoteca Universitária. Brincadeira de Faz de Conta. Formação Continuada.

\section{The importance of the make-believe play in early childhood education from the teachers' gaze}

\begin{abstract}
This article is a cut of a master's degree research in education that had as main objective to investigate the contributions of a University Toy Library, created at the University of Pernambuco, with the purpose of promoting Continuing Training for Early Childhood Education teachers and also attending children of this level of schooling, offering them play experiences. The cut presented here is based on the conceptions of teachers from Early Childhood Education, reflecting on the contributions of the makebelieve play for children and for the pedagogical practice, from one of the continuing trainings for teachers developed in the University Toy Library. Through action research, it was possible to conclude that the make-believe play contributes to the learning and development of the child from Early Childhood Education in an imaginative and creative way and that exerts, in the teachers' pedagogical practice, a pedagogical surplus value concerning the necessary interaction between play and learning.
\end{abstract}

Keywords: University Toy Library. Make-believe Play. Continuing Teachers Training.

\footnotetext{
1 Mestra em Educação pela Universidade de Pernambuco. Universidade de Pernambuco. E-mail: isadhoralucena@gmail.com. 2 Doutora em Ciências da Educação pela Universidade do Porto-Portuga. Professora na Universidade de Pernambuco. Email: fatimamaria18@gmail.com.
} 


\section{Introdução}

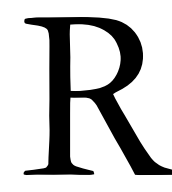

efletir sobre a contribuição da brincadeira de faz de conta para a criança e os impactos desta brincadeira para a prática pedagógica de professoras da Educação Infantil, de quatro municípios da Zona da Mata Norte do estado de Pernambuco, constitui o principal objetivo deste artigo.

A pesquisa realizada promoveu formações continuadas para professoras da Educação Infantil de municípios da Zona da Mata norte do Estado de Pernambuco, o processo partiu de uma pesquisa de mestrado, tendo como um dos objetivos, fornecer formações sob a temática do brincar. Subdivididas em três áreas: brincadeiras e jogos, a brincadeira de faz de conta e a contação de história, constituem temas relevantes no dia a dia em sala.

As formações desenvolveram-se na Universidade de Pernambuco - UPE, Campus Mata Norte, no espaço da Brinquedoteca Universitária. O processo das formações continuadas, basearam-se no brincar, compreendendo que o brincar não se distancia do cotidiano educativo. Jogos, brinquedos e brincadeiras tradicionais e contemporâneas, atividades e dinâmicas lúdicas estabeleceram guias para a formulação das formações, colaborando nos momentos teóricos e práticos. Cabe destacar, que além de desses elementos brincantes, o compartilhamento de experiências, os diálogos, as falas, as sugestões, reflexões e dúvidas das professoras contribuíram ainda mais no momento de fomento do aprendizado e conhecimento.

O faz de conta, no âmbito da brincadeira, recebe diversas denominações: "brincadeira sociodramática”, "brincadeira imaginativa”, “jogo imaginativo”, "jogo de papéis” ou "jogo simbólico”, e é fundamental para o desenvolvimento infantil. Por meio dela, a criança imagina, fantasia, dramatiza, representa, cria e recria tudo que está à sua volta. Para Kitson (2006), por meio da brincadeira de faz de conta,

[..] as crianças demostram uma crescente consciência do seu entorno social, assumindo papéis sociais conscientemente e, ao fazê-lo, vivenciam ativamente relacionamentos humanos por meio da representação simbólica (KITSON, 2006, p. 109).

Para Bomtempo (2011, p. 57), quando vemos uma criança brincando de faz-de-conta, sentimonos atraídos pelas representações que ela desenvolve: “A primeira impressão que nos causa é que as cenas se desenrolam de maneira a não deixar dúvida do significado que os objetos assumem dentro de um contexto". Isto quer dizer que o faz de conta, proporciona à criança a socialização, a troca de papéis sociais vivenciados conscientemente, ou seja, quando a criança imagina, está consciente da sua ação enquanto brinca.

$\mathrm{Na}$ sequência destas ideias, em relação à formação continuada, encontra-se na Lei de Diretrizes e Bases da Educação Nacional - LDB (BRASIL, 1996, p. 20), em seu Art. 61, \ II e III, que a formação dos profissionais da educação deverá ter como fundamentos no que se refere à formação continuada: “[...] II - 
a associação entre teorias e práticas, mediante estágios supervisionados e capacitação em serviço; III aproveitamento da formação e experiências anteriores, em instituições de ensino e em outras atividades". Desta maneira, a formação do/a professor/a deverá seguir a capacitação, envolvendo a teoria e prática, a partir das experiências anteriores dos profissionais da educação.

No entanto, é necessário pontuar que, nos estudos relacionados à formação continuada de professores/as da Educação Infantil, identifica-se uma pequena oferta de formações continuadas para essa primeira etapa da educação básica. E ainda, quando a formação continuada envolve o brincar ou a ludicidade, encontram-se simplórios estudos sobre esta temática. É, pois, nessa perspectiva que, neste texto, reitera-se a importância de se desenvolver formações continuadas que tenham como eixo o brincar nas instituições de Educação Infantil, uma vez que o brincar é "[...] uma atividade fundamental no ser humano, a começar porque funda o ser humano em nós: aquilo que define - inteligência, criatividade, simbolismo, emoção e imaginação" (FORTUNA, 2005, p. 67). Nesse sentido, o brincar está presente na vida da criança como algo relevante para o desenvolvimento da vida humana e o/a professor/a, por meio das formações continuadas, deve buscar aprimorar e atualizar a sua prática de maneira que esta favoreça o brincar e a aprendizagem de modo a permitir o desenvolvimento integral da criança.

Com relação à organização textual deste artigo, convém esclarecer que, para além desta introdução, trazem-se considerações sobre a brincadeira de faz de conta, apresentam-se os procedimentos metodológicos adotados na pesquisa e procede-se à análise de uma oficina - realizada com professoras da Educação Infantil que foram sujeitos desta investigação - a qual foi intitulada de "o mundo do faz de conta: brincando com o espelho". Por fim, apresentam-se as conclusões a que se chegou com este estudo.

\section{A brincadeira de faz de conta}

A criança brinca com uma boneca, lava sua cabeça, esfrega o sabonete em seu corpo, enxuga e veste sua roupa, ao mesmo tempo canta uma música. Outras crianças, agora, estão dentro de carros (caixas de papelão), pedestres atravessam a rua e escutam-se buzinas saindo da caixa de papelão e arrancadas de carros no sinal de trânsito. Estas cenas descritas têm a ver com crianças brincando de faz de conta. Quando se observam crianças brincando desta maneira, já se percebe que a imaginação está sendo desenvolvida. Cabe, pois, encontrar elementos do teatro, cenas de um filme e até mesmo uma realidade já vivida pela criança.

Smith (2006) esclarece que, nessa descrição do faz de conta, grande parte do brincar da criança pré-escolar é simbólico. Para o referido autor, se duas ou mais crianças estiverem juntas, envolvidas na mesma brincadeira, esse brincar é sociodramático. Ou seja, "este brincar sociodramático pode favorecer as habilidades de linguagens e desempenho de papéis" (SMITH, 2006, p. 27). E, nesse sentido, afirma que,

As crianças fingem que a ação ou um objeto têm significados diferentes do seu significado usual; por exemplo, se uma criança gira os braços, diz "biii-biii" e distribui 
pedacinhos de papel, ela está fingindo que está dirigindo um ônibus, buzinando e distribuindo as passagens. Se essas ações estiverem suficientemente integradas, podemos dizer que a criança está dramatizando ou desempenhando um papel (no caso, fingindo ser um motorista de ônibus) (SMITH, 2006, p. 27).

Vygotsky (2007) compreende que o faz de conta desempenha um importante papel na brincadeira quando aparece tanto a ação na esfera imaginativa numa situação, como na criação das intenções voluntárias e nas formações dos planos da vida real, constituindo-se assim, no mais alto nível do desenvolvimento pré-escolar. Além disso, realça a importância do brinquedo na brincadeira de faz de conta: "no brinquedo, a criança opera com significados desligados dos objetos e ações aos quais estão habitualmente vinculados [...], no brinquedo, ela inclui, também ações reais" (VYGOTSKY, 2007, p. 116).

Leontiev (2016, p. 141) diz que o faz de conta como "jogo de dramatização desenvolvido já é uma espécie de atividade "pré-estética"'. Analisa o jogo de dramatização e distingue-o em dois atributos; em "primeiro lugar, ele não reflete a atividade da personagem retratada de forma generalizada, mas, reproduz aquilo que é típico nele". Por outro lado, afirma que “[...] não há uma imitação ou uma mímica direta, pelo contrário, estamos tratando aqui com uma deliberada construção artística guiada por alguma ideia inicial da criança". O segundo atributo, "principal do verdadeiro jogo de dramatização é que se torna a personagem cujo papel irá representar, mas também como ela o fará, quão perfeitamente ela comunicará o conteúdo objetivo expresso no papel”.

Kitson (2006, p. 119) acredita que, "se essas áreas de faz de conta tornarem-se uma oficina de automóveis e uma ilha deserta serão criados novos potenciais de aprendizagem”. Assim também, se o adulto interagir com as crianças, criando desafios e obstáculos a serem superados e oferecer também espaços de faz de conta adequados às necessidades das crianças, conquistará ainda mais áreas de aprendizagem potencializantes. A brincadeira de faz de conta compreendida como um momento de aprendizagem, favorece ao/a professor/a um eixo norteador, direcionando com mais ludicidade sua prática. Assim,

O que estamos dizendo é que esse brincar pode ser expandido por meio da intervenção direta do adulto com mínimas mudanças qualitativas na atividade, mas com diferenças muito significativas no potencial de aprendizagem para a criança. Essa intervenção precisa ser sensível às necessidades das crianças e operar na fantasia delas. $\mathrm{O}$ papel do adulto é fornecer uma estrutura dentro da qual as crianças possam interagir - é contestar, definir problemas a serem resolvidos, incentivar as crianças a testarem ideias e, talvez, o mais importante, mostrar às crianças estratégias pessoais de aprendizagem (KITSON, 2006, p. 109).

Kishimoto (2011, p. 39), sinaliza que "a brincadeira de faz-de-conta, também conhecida como simbólica, de representação de papéis ou sociodramática, é a que deixa mais evidente a presença da situação imaginária". No entanto, "o faz-de-conta permite não só a entrada no imaginário, mas a expressão de regras implícitas que se materializam nos temas das brincadeiras". E ainda "é importante registrar que o conteúdo do imaginário provém de experiências anteriores adquiridas pelas crianças, em diferentes contextos". 
Com base nas ideias acima apresentadas, é possível compreender que a brincadeira de faz de conta desenvolve habilidades de linguagens, ou seja, o brincar traz em sua ação o diálogo que acompanha o desenvolvimento infantil, seja entre os pares ou individualmente. Ressalta-se o brinquedo como elemento importante, por meio do qual a criança disponibiliza significados diferentes, imaginativos sobre qualquer objeto que ela perceba como brinquedo. $\mathrm{O}$ faz de conta também se constitui em um espaço de aprendizagem e de desenvolvimento e possibilita à criança desempenhar papéis já vividos, representando atitudes dos adultos, reconstruindo situações, imaginando ocasiões voluntárias do cotidiano e dramatizando momentos perfeitamente semelhantes.

É, portanto, no âmbito destas reflexões que, nos próximos itens deste artigo, relata-se uma experiência de formação continuada na perspectiva da brincadeira de faz de conta com professoras da Educação Infantil.

\section{Procedimentos metodológicos}

No que toca aos procedimentos metodológicos desta pesquisa, conforme foi anteriormente referido, fez-se opção pela abordagem qualitativa, com ênfase na pesquisa-ação, uma vez que esta propicia a construção de novas abordagens, revisão e criação de novos conceitos e categorias durante a investigação (MINAYO, 2016).

Optou-se pela pesquisa-ação levando-se em consideração a necessidade de acompanhamento e intervenção em situações da prática pedagógica de professoras da Educação Infantil no âmbito deste estudo. A pesquisa-ação é,

[...] um tipo de pesquisa com base empírica e realizada em estreita associação com uma ação ou com a resolução de um problema coletivo e no qual os pesquisadores e os participantes representativos da situação e do problema estão envolvidos de modo cooperativo ou participativo (THIOLLENT, 2011, p. 20).

Por meio da pesquisa-ação, busca-se realizar um processo de mudança no sentido de melhorar o contexto pesquisado, melhorar a prática (RICHARDSON; RODRIGUES, 2013). Por meio desta pesquisa, foi proposta a inserção do brincar nas práticas pedagógicas como perspectiva lúdica para professoras da Educação Infantil de quatro municípios da Zona da Mata Norte do estado Pernambuco

Esta investigação consubstanciou-se num estudo realizado em parceria com quatro municípios da Zona da Mata Norte do estado de Pernambuco que se tornaram parceiros da Brinquedoteca da Universidade de Pernambuco, Campus Mata Norte. Ressalta-se que essa parceria consistiu, por parte da Universidade de Pernambuco, na oferta de formações continuadas para professoras da Educação Infantil que tivessem como eixo principal o brincar e que essa Brinquedoteca servisse de espaço brincante aos estudantes da Educação Infantil desses e de outros municípios. Com relação à contrapartida dos municípios para a formação da parceria, foi solicitado a estes que contribuíssem com brinquedos e materiais para a Brinquedoteca e, dessa forma, foi firmada a parceria. 
Foram sujeitos desta investigação professoras da Educação Infantil dos municípios parceiros, totalizando em média, 100 professoras. A coleta de dados foi realizada por meio de oficinas pedagógicas, prioritariamente. Vieira (2002), define que em uma oficina as questões científicas e metodológicas são estudadas a partir da prática. Nas oficinas, a primazia sempre é da ação, mas não desmerece a teoria.

Para a realização das oficinas pedagógicas nesta pesquisa, foi utilizada a "dinâmica de atuação docente" defendida por Delizoicov e Angotti (2009), a qual se caracteriza por momentos pedagógicos desenvolvidos em oficinas e que tem ampla aproximação com as etapas da pesquisa-ação, opção metodológica que orientou esta pesquisa. Essa dinâmica obedece às seguintes etapas: a problematização inicial, a organização do conhecimento e a aplicação do conhecimento.

Neste artigo, tem-se como objeto de análise uma oficina - realizada com as professoras sujeitas desta pesquisa - que esteve subordinada ao tema "o mundo do faz de conta: brincando com o espelho". Nessa oficina, foram realizadas dinâmicas, brincadeiras e jogos como sugestão para que as professoras pudessem desenvolvê-los com as crianças da Educação Infantil no âmbito de suas práticas pedagógicas. Convém ressaltar que a análise aqui realizada centra-se exclusivamente nas questões que têm como eixo a brincadeira de faz conta. A análise dos dados nesta investigação foi realizada por meio da análise de conteúdo, na perspectiva analítico-descritiva,

Um conjunto de técnicas de análise das comunicações visando a obter, por procedimentos sistemáticos e objetivos de descrição do conteúdo das mensagens, indicadores (quantitativos ou não) que permitam a inferência de conhecimentos relativos às condições de produção/recepção (variáveis inferidas) destas mensagens (BARDIN, 2011, p. 47).

Neste tipo de análise, pretende-se compreender melhor o discurso e explorar todas as etapas da pesquisa através dos instrumentos metodológicos a serem utilizados, que nesta pesquisa foram a oficina pedagógica, a entrevista coletiva e a observação participante.

$\mathrm{Na}$ próxima seção, procede-se a uma análise dos dados coletados durante uma formação continuada realizada com as professoras sujeitas desta pesquisa que esteve subordinada à temática da brincadeira de faz de conta. Dessa forma, tem-se como objeto desta análise certas dimensões suscitadas na investigação com base em questionamentos feitos às professoras na oficina pedagógica, a saber: percepção das professoras sobre a brincadeira de faz de conta; contribuições da brincadeira de faz de conta para a aprendizagem da criança na Educação Infantil; contribuições da brincadeira de faz de conta para a prática pedagógica na Educação Infantil. Assim sendo, analisa-se aqui os depoimentos de três grupos de professoras da Educação Infantil que participaram da formação subordinada ao tema: "o mundo do faz de conta: brincando com o espelho". Esses grupos estão aqui identificados como Grupos de Professoras GP 1, Grupos de Professoras - GP 2 e Grupos de Professoras - GP 3. 


\section{Percepção das professoras sobre a brincadeira de faz de conta}

No que se refere à brincadeira de faz de conta, foi possível identificar entre os discursos das professoras diversas percepções, no entanto, as falas abaixo revelam a representatividade da brincadeira de faz de conta para a criança. Reitera-se que as falas a seguir foram selecionadas, porque sintetizam o entendimento das professoras sobre a brincadeira de faz de conta, principalmente, por haver uma associação do faz de conta à imaginação e à criatividade das crianças.

O faz de conta representa para a criança experiências vivenciadas e experiências da imaginação. [...] Mundo da criança, o seu imaginário (GP 1).

A brincadeira, a imaginação, a criatividade, o desafio. Representa o desenvolvimento da criatividade e da imaginação (GP 2).

Representa o mundo mágico, a imaginação, a criatividade. O faz de conta na maioria das vezes, é uma cena que ela [a criança] presenciou, em algum lugar, elas também usam os brinquedos para criar o seu mundinho, a sua imaginação (GP 3).

Percebe-se nos depoimentos das professoras a compreensão da brincadeira de faz de conta como um momento de estimulação da imaginação e da criatividade. Isso acontece quando a criança fantasia ou revive momentos já experimentados, ou seja, já vividos. Para Leontiev (2016, p. 132), “a característica básica, a coisa que mais chama nossa atenção nessas brincadeiras é a existência de uma situação imaginária". Assim, a imaginação está presente na brincadeira de faz de conta. No que se refere à criatividade, no momento da brincadeira frisada pelas professoras, Moyles (2002, p. 84) afirma que "poderíamos dizer que o brincar leva naturalmente à criatividade, porque em todos os níveis do brincar as crianças precisam usar habilidades e processos que proporcionam oportunidades de ser criativo".

Observa-se no trecho da fala do GP3 que "[...] o faz de conta na maioria das vezes é uma cena que ela (a criança) presenciou, em algum lugar". Percebe-se, neste depoimento, que a brincadeira de faz de conta propõe a assimilação de momentos sociais da criança e incita a imaginação, pois "ideias e ações adquiridas pelas crianças provêm do mundo social, incluindo a família e o seu círculo de relacionamento, o currículo apresentado pela escola, as ideias discutidas em classe" (KISHIMOTO, 2011, p. 39). Deste modo, a brincadeira de faz de conta favorece, pela imaginação, a representação de situações reais e irreais vivenciadas ou não, pela criança, além de papéis como o pai, a mãe, o/a professor/a, entre outros atores encontrados na sua vida cotidiana no momento da brincadeira. Isso mostra que não se trata de uma atividade totalmente desconectada com o mundo social da criança, porque, "quando brinca, a criança toma certa distância da vida cotidiana, entra no mundo imaginário (KISHIMOTO, 2011, p. 24). Muito pelo contrário, pois, como visto, é uma forma de a criança assimilar o seu entorno.

Essas ideias assemelham-se à perspectiva de Smith (2006, p. 27), quando este apresenta as seguintes palavras:

Muitos teóricos e educadores acreditam que a experiência do brincar é a maneira ideal de desenvolver a criatividade e a imaginação. Isso porque as crianças ficam livres para experimentar novas ideias no brincar e podem expressar à sua própria maneira, 
especialmente no jogo simbólico e no brincar de faz de conta, em que podem inventar papéis e criar uma história, guiada livremente pela própria imaginação.

Percebe-se nos discursos das professoras e nos conceitos teóricos apresentados, a presença da imaginação e da criatividade no brincar, partindo do entendimento de que a brincadeira de faz de conta é provocada e aguçada por meio do imaginar e do criar. Quando as crianças brincam, experimentam novas ideias, criam novos conceitos e histórias, a partir dos momentos quando imaginam e das ações criativas.

Ressalta-se que as professoras, sujeitas desta pesquisa, entendem que a brincadeira de faz de conta proporciona à criança momentos imaginativos, criativos, simulados pelo mundo cotidiano infantil e expressa, à sua maneira, as representações sociais em forma de papéis, ou em cenas vivenciadas.

\section{Contribuições da brincadeira de faz de conta para a aprendizagem da criança na Educação Infantil}

Na sequência desta análise, descrevem-se trechos de discursos das professoras investigadas sobre as contribuições da brincadeira de faz de conta para a aprendizagem da criança, que nesta pesquisa constituiu outro aspecto que se teve em conta. E, dessa forma, quando indagadas, as professoras se expressaram da seguinte forma:

Sim, contribui para a realização do aprender com o lúdico em relação à imaginação das crianças (GP 1).

O faz de conta pode contribuir muito para o desenvolvimento escolar, pois a criança retrata a realidade através do faz de conta e o professor deve trabalhar esse elo, imaginário e realidade (GP 2).

Sim, contribui porque estimula o seu pensar, de uma forma leva à aprendizagem(GP 3).

Observa-se, nos depoimentos das professoras supracitadas, o faz de conta como uma brincadeira que contribui para a aprendizagem da criança. É possível encontrar, nos discursos dessas professoras, elementos que se assemelham ao que Kitson (2006) discute, quando afirma que, ao criar um posto de correio e um reino da fantasia, as crianças lidam com matemática, linguagem, habilidades sociais, habilidades de manipulação de automóveis e uma ilha deserta e que, assim, serão criados novos potenciais de aprendizagem. Assim sendo, por intermédio da brincadeira de faz de conta, é possível proporcionar aprendizagens de diversas áreas e o desenvolvimento de habilidades potencializantes, intermediadas pela imaginação, conforme salienta Vygotsky (2007), quando este diz que o que define o brincar é a situação imaginária.

$\mathrm{Na}$ sequência destas reflexões, é pertinente referenciar novamente Smith (2006), quando este reconhece a diversidade de habilidades que a brincadeira de faz de conta estimula, principalmente, para o desenvolvimento da criança. E mais: quando se pensa a criatividade como elemento da brincadeira de faz de conta, percebe-se a amplitude que esta habilidade proporciona, isto porque "a criatividade, então, está 
extremamente ligada às artes, à linguagem e ao desenvolvimento da representação do simbolismo" (MOYLES, 2002, p. 83).

Neste sentido, as professoras investigadas demonstraram um entendimento entre a relação da brincadeira de faz de conta e a aprendizagem da criança, como um elo entre o aprender e o brincar. Os relatos também refletem a importância dessa brincadeira para o desenvolvimento de habilidades instigadas pela imaginação. Assim, as professoras demonstram uma compreensão de que o imaginar está associado também à brincadeira de faz de conta. E mais, que essa forma de brincar promove, consequentemente, a aprendizagem na Educação Infantil.

\section{Contribuições do faz de conta para a prática pedagógica de professores na Educação Infantil}

No que tange à contribuição de faz de conta para a prática pedagógica das professoras da Educação Infantil, quando questionadas, as professoras se posicionaram da seguinte forma:

[...] contribuindo na aprendizagem, no desenvolvimento social, tornando a prática do professor significativa e dinâmica (GP 1).

O mundo do faz de conta da criança, contribui para a prática pedagógica do professor, ou seja, brincando também se aprende, só basta o professor querer e se disponibilizar para enriquecer e aprimorar sua prática pedagógica (GP 2).

O faz de conta oferece esta oportunidade de brinca]. [...] Nesse sentido, o professor que tem esta visão, perceberá que esta prática facilitará o processo de ensino aprendizagem, já que despertar o interesse e insere a criança no mundo do saber e aprender, será tão natural como brincar (GP 3).

Kitson (2006, p. 120) revela que "somente quando os educadores reconhecem a importância de seu papel no brincar imaginativo é que eles poderão intervir e começar a desenvolver o verdadeiro potencial dessa atividade". Deste modo, observa-se, no discurso das professoras, sobretudo os trechos destacados em negrito, referências a uma ligação entre a brincadeira de faz de conta e a prática pedagógica do/da professor/a, ou seja, o brincar como aliado à prática docente. Nesse âmbito, vale à pena recorrer ao que diz Tardif sobre a importância das ações que são mobilizadas por meio da prática pedagógica, a qual é colocada pelo autor nos seguintes termos:

[...] a prática educacional mobiliza duas grandes formas de ação: por um lado, ela é uma ação guiada por normas e interesses que se transformam em finalidades educativas; por outro lado, é uma ação técnica e instrumental que busca se basear num conhecimento objetivo [...] (TARDIF, 2014, p. 56).

Sob essa perspectiva, é possível reconhecer a relação do brincar à prática, compreendendo esse movimento, como sinaliza Tardif (2014), enquanto uma ação guiada por normas e interesses, ou seja, do brincar aliado à prática pedagógica, tendo em vista potencializar o desenvolvimento da criança. De modo que a ação da brincadeira seja direcionada tendo em vista alcançar certas finalidades educativas, 
constituindo a relação do brincar e aprender na escola, sendo também um instrumento da prática pedagógica, pois "defender o brincar na escola, não significa negligenciar a responsabilidade sobre o ensino, a aprendizagem e o desenvolvimento" (FORTUNA, 2000, p. 152). No entanto, o importante é compreender que "[...] uma atividade lúdica representa um momento prazeroso diferenciado das tarefas tipicamente escolares, onde o rasgo de espontaneidade é possível" (FORTUNA, 2000, p. 151). Deste modo, o brincar e a aprendizagem não são dicotômicos, andam paralelamente, como um conjunto de ações para o desenvolvimento da criança.

Ainda no âmbito da análise dos discursos das professoras anteriormente demonstrados, destacamse conteúdos que indicam o uso da brincadeira de faz de conta na prática de sala de aula da Educação Infantil. A esse respeito, Smith (2006, p. 32), afirma que "a aprendizagem do brincar de faz de conta é sociodramático é prazerosa para as crianças e para os professores e é uma maneira de promover um ativo envolvimento adulto-criança". Assim sendo, pode-se dizer que a brincadeira de faz de conta expressa em sua prática as experiências e conhecimentos da criança, um elemento que contribui para a prática do/da professor/a, sendo também um componente importante para o estreitamento da relação do/da professor/a com as crianças.

Em síntese, pode-se dizer que as ideias aqui apresentadas sobre contribuições da brincadeira de faz de conta para o desenvolvimento integral de crianças da Educação Infantil, oriundas dos discursos das professoras sujeitas desta pesquisa, permitiram concluir que as professoras investigadas reconhecem e enaltecem as contribuições da brincadeira de faz de conta para a prática pedagógica, para a aprendizagem das crianças e para o desenvolvimento de habilidades, uma vez que esta aguça a imaginação da criança e lhes permite a vivência de papéis sociais.

\section{Conclusões}

No que se refere à importância da brincadeira de faz de conta na Educação Infantil, os dados coletados no âmbito da oficina realizada com as professoras sujeitas desta investigação e intitulada: "o mundo do faz de conta: brincando com o espelho", permitiram concluir que a brincadeira de faz de conta contribui para a aprendizagem e o desenvolvimento da criança da Educação Infantil de forma imaginativa e criativa e que exerce, na prática pedagógica de professores/as da Educação Infantil, uma mais valia pedagógica no que toca à necessária interação entre o brincar e o aprender.

No âmbito destas conclusões, convém ressaltar o que se pôde depreender a partir dos recortes de falas apresentados quanto à percepção das professoras sobre a brincadeira de faz de conta, as contribuições da brincadeira de faz de conta para a aprendizagem da criança na Educação Infantil e sobre as contribuições da brincadeira de faz de conta para a prática pedagógica na Educação Infantil. 
Com relação à percepção das professoras sobre a brincadeira de faz de conta, pode-se concluir uma compreensão desta brincadeira, caracterizada como criativa e imaginativa, estimulante na construção de novos significados ao mundo da criança, habilidades e competências. Oliveira (2013, p. 4), confirma esta ideia, ao apresentar as seguintes palavras:

$\mathrm{Na}$ brincadeira a criança consegue aflorar sua criatividade sendo ela mesma, sem medo da imposição do adulto. Somente brincando a criança consegue viajar em um mundo ilusório cujo autor é ela, pois o brincar é uma atividade onde as crianças criam novos fatos, novos ambientes, novos brinquedos, dão novos sentidos às brincadeiras, conseguem representar, cantar, subir em palcos, dançar, tudo por intermédio da sua criatividade na brincadeira.

A brincadeira exerce grande influência no desenvolvimento da criança, principalmente na Educação Infantil, uma vez que possibilita momentos imaginativos, criativos, simulados pelo o mundo cotidiano infantil e por meio da qual a criança expressa à sua maneira as representações sociais em forma de papéis ou cenas vivenciadas.

No âmbito da brincadeira de faz de conta em relação à aprendizagem da criança, é possível perceber, nos depoimentos das professoras, uma afinidade nesta relação, pois contribui para a aprendizagem e também para o desenvolvimento da criança, como atividade imaginativa e criativa, sem desmerecer a importância que a brincadeira sociodramática, como pode ser chamada, exerce na prática pedagógica de professores/as da Educação Infantil, uma ponte de interação entre o brincar e o aprender.

Assim, faz-se necessário resgatar o que Bomtempo (2011) discute. A primeira impressão que se pode ter, ao observar a brincadeira de faz de conta, é que as cenas se desenrolam de maneira a não deixar dúvida quanto ao significado que os objetos assumem dentro de um contexto. Em outras palavras, o faz de conta tem características próprias no brincar da criança e está baseado no entendimento desta atividade lúdica como expressão do mundo da criança, no qual ela constrói e reconstrói novos significados conferidos aos objetos ou ações que determinam a brincadeira.

No tocante ao faz de conta na relação com a prática pedagógica, apresentam-se conclusões a respeito dessa brincadeira, baseando-se nas percepções das professoras investigadas, sendo esta uma atividade que auxilia na aprendizagem, no desenvolvimento e favorece a criatividade, despertando o interesse da criança em aprender por meio da imaginação e na representação de papéis sociais. Isto vem de acordo ao entendimento de Moyles (2006, p 109), uma vez que, quando as crianças brincam de faz de conta, "[...] demostram uma crescente consciência do seu entorno social, assumindo papéis sociais conscientemente e, ao fazê-lo, vivenciam ativamente relacionamentos humanos por meio da representação simbólica".

Sobre a formação lúdica, Fortuna (2005, p. 91), por sua vez, aponta que:

[...] diz respeito àquilo que os professores sabem, vivenciam e sentem em relação à ludicidade e que define seu modo de ser e seus conhecimentos no âmbito do brincar, com decisivas implicações tanto para a sua prática pedagógica, quanto para as práticas formativas institucionais relativas ao jogo e à educação. 
A partir disto, percebe-se a formação lúdica como necessária para que professores/as compreendam a importância do brincar na Educação Infantil, pois quando a criança brinca, assimila o mundo à sua maneira, sem compromisso com a realidade, pois sua interação com o objetivo não depende da natureza do objeto, mas da função que a criança the atribui (PIAGET, 1971). Ou seja, a brincadeira proporciona à criança desenvolvimento social, imaginativo e intelectual, além de proporcionar-lhe habilidades e competências essenciais, vida estudantil e social.

Ressalta-se que, quando o/a professor/a reconhece essas possibilidades por intermédio da brincadeira de faz de conta, estas passam a favorecer a interação entre o professor e as crianças e, ainda, possibilitar uma prática mais lúdica e prazerosa. Fortuna (2000, p. 108), enfatiza que, quando a criança brinca, "intervenções efetivas podem canalizar essa aprendizagem, ajudando a criança a construir novos dilemas e desafios, encorajando-a e apoiando-a, e expandindo e motivando a competência e o desempenho linguístico". Assim sendo, a brincadeira de faz de conta estimula a aprendizagem e o interesse das crianças por se diferenciar das atividades normalmente presentes nas escolas, ausentes da vivência da brincadeira, do lúdico.

A partir desse entendimento, as professoras investigadas compreendem o faz de conta como representatividade da criança no brincar sobre seu convívio, suas ações cotidianas e dos sujeitos com os quais convive e/ou que pertencem ao meio social do qual ela também faz parte.

\section{Referências}

BARDIN, L. Análise de conteúdo. Lisboa: Edições 70 - Brasil, 2011.

BOMTEMPO, E. A brincadeira de faz-de-conta: lugar do simbolismo, da representação, do imaginário. In: KISHIMOTO, T. M. (Org.). Jogo, brinquedo e a educação. 5. ed. São Paulo: Cortez, 2011,. p. 5771.

BRASIL. Mistério da Educação. Lei no 9.394, de 20 de dezembro de 1996. Lei de Diretrizes e Bases da Educação Nacional - LDB. Estabelece as diretrizes e bases da educação nacional. Diário Oficial da República Federativa do Brasil, Brasília, 23 dez. 1996.

DELIZOICOV, D.; ANGOTTI, J. A. Ensino de ciências: fundamentos e métodos. 3. ed. São Paulo: Cortez, 2009.

FORTUNA, T. R. Sala de aula é lugar de brincar? In: XAVIER, M. L. M.; ZEN, M. I. H. D. (Org.). Planejamento em destaque: análises menos convencionais. 4. ed. Porto Alegre: Mediação, 2000. p. 147164. 
FORTUNA, T. R. A formação lúdica do educador. In: MOLL, J. (Org.). Múltiplos alfabetismo: diálogos com a escola pública na formação de professores. Porto Alegre: Editora da UFGRS, 2005. p. 107-121.

KISHIMOTO, T. M. A brinquedoteca no contexto educativo brasileiro e internacional. In: OLIVEIRA, V. de. (Org.). Brinquedoteca: uma visão internacional. Petrópolis, RJ: Vozes, 2011. p. 15-35.

KITSON, N. "Por favor, Srta. Alexander: você pode ser o ladrão?" O brincar imaginativo: um caso para a intervenção adulta. In: MOYLES, J. R. (Org.). A excelência do brincar: a importância da brincadeira na transição entre Educação Infantil e os anos inicias. Porto Alegre: Artmed, 2006. p. 108-120.

LEONTIEV, A. N. Os princípios psicológicos da brincadeira pré-escolar. In: VYGOTSKII, L. S.; LURIA, A. R.; LEONTIEV, A. N. (Org.). Linguagem, desenvolvimento e aprendizagem. 14. ed. São Paulo: Ícone: Editora da Universidade de São Paulo, 2016. p. 119-142.

MINAYO, M. C. de S. O desafio da pesquisa social. In: DESLANDES, Suely F.; GOMES, R.; MINAYO, M. C. de S. (Org.). Pesquisa social: teoria, método e criatividade. Petrópolis, RJ: Vozes, 2016. p. 09-29.

MOYLES, J. R. Só brincar? O papel do brincar na Educação Infantil. Porto Alegre: Artmed Editora, 2002.

MOYLES, J. R. Introdução. In: MOYLES, J. R. A excelência do brincar: a importância da brincadeira na transição entre Educação Infantil e anos iniciais. Porto Alegre: Artmed, 2006. p. 11-21.

OLIVEIRA, E. M. R. de.; RUBIO, J. de A. S.. O Faz de Conta e o Desenvolvimento Infantil. Revista eletrônica saberes da educação, FAC São Roque, São Roque-SP, v. 4, n. 1, 2013. Disponível em: $<$ http://docs.uninove.br/arte/fac/publicacoes/pdf/v4-n1-2013/Elisangela.pdf $>$. Acesso em: 15 set. 2017.

PIAGET, Jean. A formação do símbolo da criança. Rio de Janeiro: Zahar, 1971.

RICHARDSON, Roberto; RODRIGUES, Luiz A. R. Investigação e Intervenção na Gestão Escolar/Metodologia do Trabalho Científico. In: Curso de Especialização em Gestão e Avaliação da Educação Pública. Módulo III. Recife, 2013.

SMITH, P. K. O brincar e os usos do brincar. In: MOYLES, Janet R. (Org.). A excelência do brincar: a importância da brincadeira na transição entre Educação Infantil e os anos inicias. Porto Alegre: Artmed, 2006. p. 25-38.

TARDIF, M. Saberes docentes e formação profissional. Petrópolis, RJ: Vozes, 2014. 
THIOLLENT, M. Metodologia da Pesquisa-ação. 18. ed. São Paulo: Cortez, 2011.

VIEIRA, E. Oficina de ensino? O quê? Por quê? Como? 4. ed. Porto Alegre: EDIPUCRS, 2002.

VYGOTSKY, L. S. A formação social da mente. 2. ed. São Paulo: Martins Fontes, 2007. 